\title{
Teaching and Practising Interdiscursivity in the Professional Areas of Engineering and Health - A Qualitative Study
}

\begin{abstract}
Knowing to write effectively is key to communication within the different interfaces of any professional role - clientfacing, colleague-facing and/or public-facing. Complaints of poor service from professionals often focus on their failure to communicate, not merely in terms of politeness and consideration, but with respect to a lack of clear explanations underlying professional decisions. In other words, the process of interpreting their specialist body of knowledge to the client appears to be a great challenge. Communication that performs a translation function between the world of the professional and that of the client is 'interdiscursive': it involves a fusion of genres. Interdiscursivity also arises in communication within the workplace, for example in seeking or giving authorisation or advice. In this article, we examine the challenges that interdiscursive communication pose, from the point of view of engineering and of health professionals, some of whom are also teachers in these fields at university level. Our findings are based on interviews we conducted with these different groups. We hereby aim to extend the theoretical and contextual framework drawn up by a previous survey study. Although the interview participants show a certain awareness of interdiscursive writing skills, the conclusions drawn from this awareness differ between the groups, as well as between the employed versus the self-employed professionals. While the former group writes in a way that rather disregards the target audience and does not see much sense in learning and training writing skills, the latter group was obliged to find ways of managing the demands they faced.
\end{abstract}

\section{Keywords}

Professional Writing; Engineers; Physiotherapy; Health Professions; Academic Writing, Interdiscursivity

\section{Introduction}

The written form of communication has become more important than ever before, with the internet, email and messenger applications making written exchange both fast and simple. This also applies to professional contexts, where excellent writing skills have become essential for a successful career (Holden 2017; Usher et al. 2014). Good texts require prior analysis of the text's goal, the target group, as well as the target group's goals - to ensure that the writers' ideas are successfully conveyed to their readership (Bétrancourt/Ortoleva/Billet 2015; Leijten et al. 2014; Neumann 2015). Professional written communication usually takes place within the respective community, which sets standards in the form of genres for text structure, wording, or content, creating in this manner the standards of everyday communication within the respective fields (Swales 1990). These genres provide "an individual's repertoire of situationally appropriate responses to recurrent situations" (Berkenkotter/Huckin 1995: ix), which enhances "the reader's chances of interpreting the writer's purpose [by taking] the trouble to anticipate what the reader might be expecting based on previous texts he or she has read of the same kind" (Hyland 2004: 5). If writers wish to take their readership into account, i.e. customers who, as they do not form part of the professional community, tend not to know how its discourse is structured, they must

* Esther Breuer

Faculty of Arts and Humanities,

University of Cologne

E-mail: ebreuer1@uni-koeln.de
Penelope Allsobrook

Faculty of Arts and Humanities

University of Cologne

E-mail:pallsobr@uni-koeln.de 
act interdiscursively: they must realise their goals either in a form that is unfamiliar to their professional contexts, or they must be strategic in applying elements of their specific professional communication in other text forms (e.g. technical terms in a marketing text). As Schriver (1997: 3) states:

\begin{abstract}
If writers $[\ldots]$ are to create documents that take readers seriously, they will need a more detailed view of readers than they have now - a view which allows them to imagine readers other than themselves actively engaging with words and pictures. Professionals will also need to be able to compare their own writing and design practices to those of others.
\end{abstract}

However, a previous survey by Breuer et al. (2015) found that in the professional contexts of engineering and health sciences, these abilities are not taught at either universities or professional schools in Germany or in the U.K.; and while students and professionals admit that writing plays a crucial role in their professional lives, they do not see the point of training writing skills.

In order to analyse professionals' management of this contradiction between attitude and reality as reported by Breuer et al. (2015), a qualitative study was set up in which both German engineers and health professionals were interviewed. The present study focuses on the following questions:

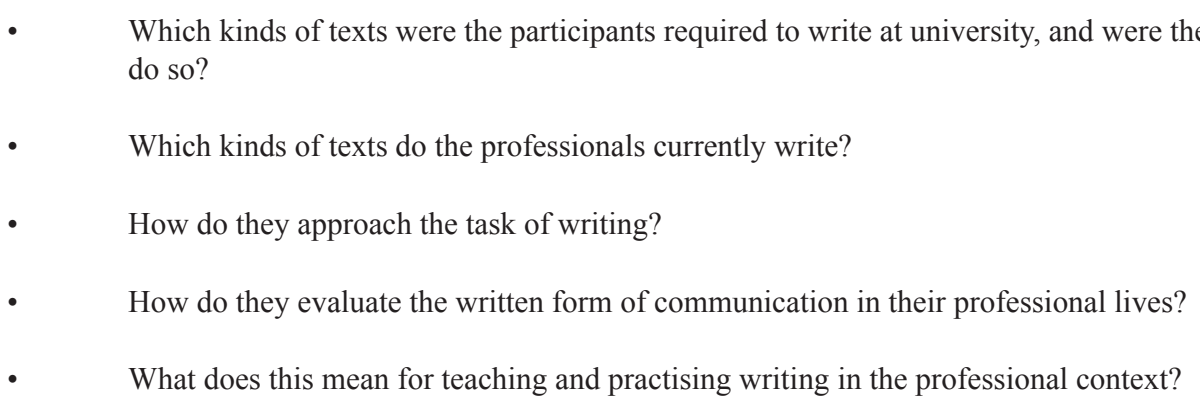

In Section 2, the backdrop to the teaching of writing for the professional context will be outlined. In Section 3, the study itself is presented in more detail, while zooming in on the key statements of the interviewees in Section 4. Our focus is on whether the professionals in the study attune their writing to the needs of their target groups before sitting down to write, and whether their texts are in fact adapted to the various groups. Thus, the aim of our study is to clarify the 'interdiscursive' reality of these specific professional areas.

\title{
2. Interdiscursivity in professional writing
}

One does not begin from scratch when creating a text but rather builds on the context in which the texts previously written have formed specific textual expectations (Curry/Lillis 2004; Kennedy/ Smith 2010) as well as on the reader's understanding of the respective genre. Genres can be seen as "situated linguistic behaviour in institutionalised academic or professional settings" (Bhatia 2002: 22); as "a rhetorical means for mediating private intentions and social exigence" (Miller 1984: 163); or as "classes of communicative events which typically possess features of stability, name recognition and so on" (Swales 1990: 9). The genre is formed by the professional practice, which in turn belongs to a professional culture (Fig. 1). There are intertextual interrelationships which exist "between and across texts, focusing primarily on text-internal properties" (Bhatia 2010: 32): All of the texts that one writes and reads operate on the basis of standards that are defined and developed over time in previously published texts, in a specific professional (or academic) field (intertextuality). Since a "profession is partly defined by the ability of its members to show that they possess a unique body of knowledge, can demonstrate certain skills, and can specify the training needed to be a member of the profession" (Schriver 1997: 68), intertextual skills are vital for a professional's standing in the community. 


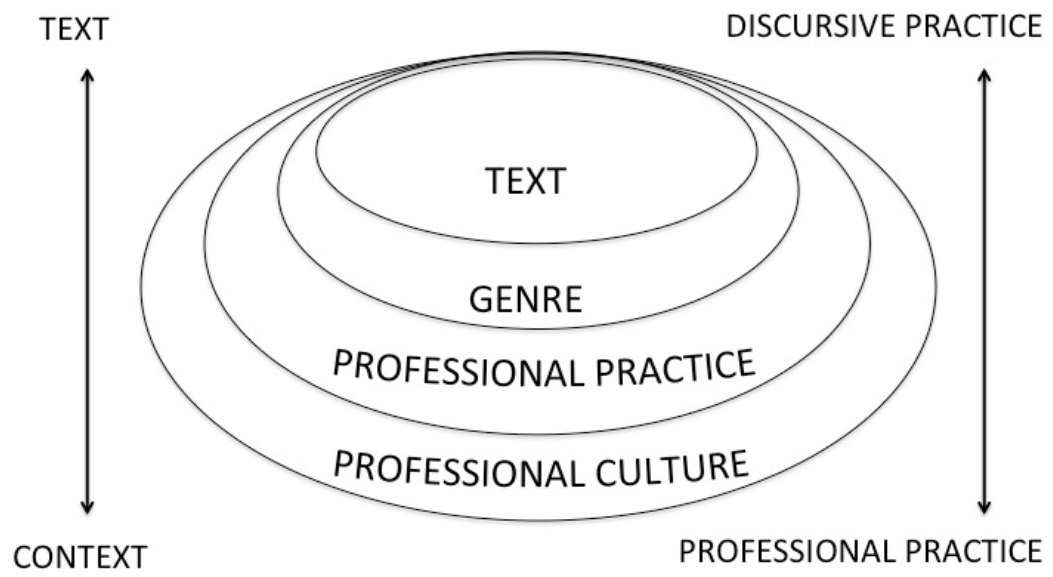

Figure 1. Levels of professional communication (Bhatia 2010: 33)

Professionals who communicate with readers outside of their professional field (e.g. patients for health professionals or customers for engineers) need to take into account that their readers are not experts within the respective field, and that they are not used to the way in which the specific discourse functions. If their communication is to be successful, the professionals need to adjust their writing to the requirements of the different target groups, while at the same time integrating aspects from a different genre into their texts (e.g. using elements from marketing texts when applying for a contract of technical instruments with a potential client) or adjusting genre elements to the audience (e.g. employing commonly used words instead of specialist terms in guidelines for patients) (interdiscursivity). This interdiscursivity is applied across all levels of discourse (Bhatia 2010: Fig. 1): One not only needs to write one's texts accordingly but also to adapt one's behaviour when communicating with customers, with craftspersons, or for example when communicating with fellow engineers on a common project.

As some of the defining contextual and disciplinary factors are well-known to the audience (Bhatia 2004, 2010; Hyland 2004; Schneider 2010; Swales 2004), there is no need to change the linguistic characteristics of the genre of a professional culture altogether: patients are unlikely to trust a health professional who gives illnesses fictional names. At the same time, patients are likely to be uncomfortable when confronted with too many professional medical terms, as this hinders not only their understanding of the illness but also the consequences of the illness for their future lives, i.e. which steps need to be taken and for what reason (Lim 2009). This type of miscommunication takes place between patients/ customers and professionals of all kinds: the former group wishes to be rest assured that the professional is an expert, while at the same time, too much professional language can lead to misunderstanding. This might in turn lead to doubting whether patients/customers have the same goals as the professionals, or that the professionals are trying to fool them with their 'professionlect' - perhaps ultimately leading to a loss of patients and clients (Lim 2009).

Professionals thus need to know and to analyse how the person they are communicating with 'thinks', what the knowledge basis is with which they work, and which form of communication they are used to, in order to use appropriate discourse (Henry 1998). At the same time, professionals need to be aware of those elements that give them credibility. Steve Bennett's (2010) diagram nicely showcases how engineers would like a recipe to look (Fig. 2), something which would perhaps be unsuitable for a reader unacquainted with technical communication. Still, even in the 'engineer-adapted' form of a recipe, wellknown elements of standard recipes are adopted here, making the professional background of the text form visible and the recipe 'believable' (Larson 1977). 


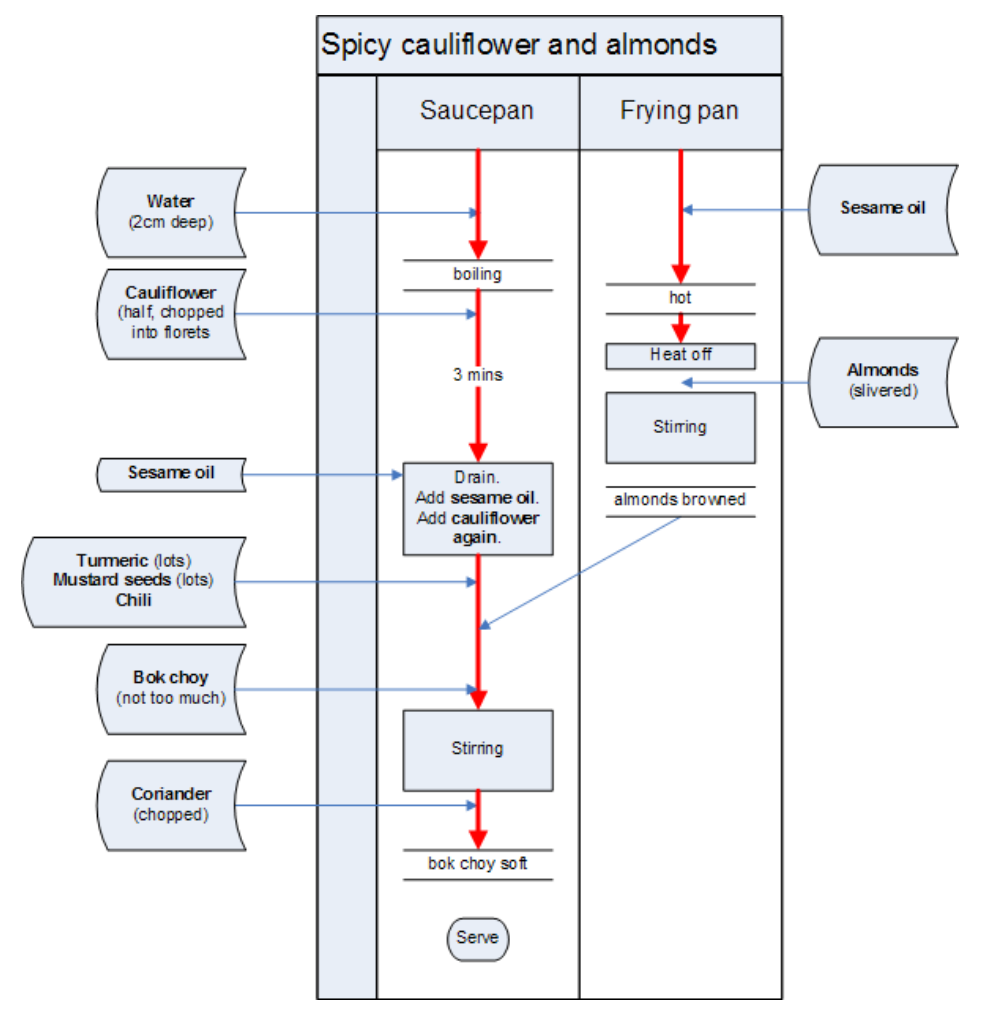

Figure 2. Cooking for engineers (Bennett 2010)

Various studies have shown that the ability to communicate interdiscursively with customers or patients is crucial for professional success - not only for the professionals themselves but also for the company/the institution they work for. A central element here is using "plain language" (Willerton 2015). This "streamlines procedures and paperwork" (Kimble 1997: 3), "reduces confusion, complaints, and claims, and [...] improves customer satisfaction", as well as "increases sales and raises the company's standing in the marketplace" (4). A fitting example comes from Murrmann (2015) in her examination of a Polish fitness trainer's communication with her target group via DVD instructions, Facebook and other forms of online written communication. She found that the trainer used a mixture of 'professionlect' as well as a very personal form of communication which was a key factor to her professional success. Her language was used in this way as an essential marketing instrument, a skill unlikely to be taught at university: the trainer was able to emphasize her expertise in the field, meaning that she was successful in meeting the needs of her readers.

Although it has been widely proven that companies benefit from good professional writing (Mead 1998; Ramey 1995; Schriver 1997,2012) (even more so if the writer is not a professional technician but a professional writer, see Hayes 1989; Pinker 2014), writing practice is neither a central topic at universities nor in companies (although concepts of teaching professional writing at universities do exist, albeit rarely, at German universities) (e.g. Hill/Griswold 2013; RamírezEcheverry et al. 2016; Rus 2015). In university programmes that offer a 'technical writer' qualification, writing and text creation make up less than a quarter of the entire course. This is possibly the result of managers' and teachers' attitudes toward writing and its learnability. Writing is very often seen in a romantic way, as being a talent, something with which one is either gifted or not (cf. Schriver 1997). The only aspects that are teachable, so goes the assumption, are grammar and orthography. These are aspects that, however, should already have been acquired at school, making classes at university and later in professional life redundant. Those who teach writing are often seen as "grammar doctors" who teach a "remedial" (Schriver 1997: 68) subject. This view is in turn often adopted by the students who sometimes even feel ashamed of their needing 
guidance, and who therefore do not want their professors to know that they have gone to a writing centre for support (personal communication with students of the writing centre at our university).

In short, both managers and professionals are aware that technical skills alone are insufficient for (personal and business) success, and that written communication is not only relevant but that it has a huge impact on one's later profession (Ramey 1995; Redish 1995, 2010). For example, up to $60 \%$ of an engineer's work time is devoted to writing (Mort et al., 2012). It is consequently no great surprise that there are books on writing successful proposals in health professions (e.g. Funk/Tornquist 2015), on style in health professions (e.g. Fondiller/Nerone 2007), on professional expression for engineers (e.g. Morris 2009) or on the teaching of technical writing (e.g. Hering 2015; Juhl 2015). However, the teaching and practice of writing is still not mandatory in Germany or in many other countries. If there are classes on writing, these focus on academic writing. The necessary skills of learning intertextuality and interdiscursivity are not explicitly taught, although this would be quite easy, as the settings of how to write within the academic community depend on intertextuality and interdiscursivity, although they are relatively fixed (Thielmann 2009). The students believe that academic writing skills will most likely not be of much use in their professional careers (Breuer et al. 2015), which "makes the task abstract and the learner confused and demotivated" (Orlova/Zeidmane 2011: 523).

In order to analyse whether this juxtaposition is perceived inside the community of health professionals and engineers, Breuer et al. (2015) set up a questionnaire asking German as well as U.K. students, teachers, writing teachers and professionals about their writing attitudes, their writing experiences and their evaluation of the importance of the writing skills that were necessary for performing expected tasks (e.g. structuring, idea generation, and knowledge about genre). The results showed that the teachers, students and practitioners had similar views within their groups - independently of whether they belonged to the health or to the engineering group. There was, however, a difference between the professionals and the students in their evaluation of the type of writing skills that are important in professional communication. Whereas the latter were of the crafts tradition (cf. Schriver 1997), in which grammar and orthography are highly valued, the professionals stressed that interdiscursive factors play a more crucial role. Still, the majority did not see any need for special writing classes.

We set up a qualitative study with a two-fold aim: (1) to understand the contradiction outlined above, namely an awareness of the need for good writing skills versus the seeming lack of interest in teaching and learning these skills; (2) to see how interdiscursive problems are understood and met by professionals. We interviewed both engineering and health professionals on their writing practices, on their views for the need and effectiveness of teaching writing skills and on the importance of writing skills for their professional futures.

\section{Methods}

The aim of the present study was to yield more insight into how engineers and health professionals evaluate the writing techniques they acquired in higher education with respect to their appropriateness and use in their later professional careers. Qualitative data were collected by conducting interviews with ten professionals, two of whom are also university teachers.

\subsection{Participants}

The ten participants in this study worked either in a larger company, in private practice, or at university, as shown in Table 1. 


\begin{tabular}{|l|l|l|l|l|}
\hline Name & Gender & Profession & Years in profession & Company \\
\hline Eng01 & female & Engineer architecture & 25 & Private business \\
\hline Eng02 & male & Engineer machines & 3 & $\begin{array}{c}\text { Employee in a larger com- } \\
\text { pany }\end{array}$ \\
\hline Eng03 & male & Engineer machines & 20 & $\begin{array}{l}\text { Employee in a larger com- } \\
\text { pany }\end{array}$ \\
\hline Eng04 & male & $\begin{array}{l}\text { Engineer software deve- } \\
\text { lopment }\end{array}$ & 19 & $\begin{array}{c}\text { Employee in a larger com- } \\
\text { pany }\end{array}$ \\
\hline Health01 & female & Physiotherapist & 14 & Private practice \\
\hline Health02 & female & Physiotherapist & 12 & Private practice \\
\hline Health03 & female & Physiotherapist & 25 & Private practice \\
\hline Health04 & male & Physiotherapist & unknown & University hospital \\
\hline TeachHealth & female & $\begin{array}{l}\text { Lecturer in Physiothe- } \\
\text { rapy }\end{array}$ & $\begin{array}{l}3 \text { (as teacher), 14 (as a } \\
\text { health professional) }\end{array}$ & University \\
\hline TeachEng & male & Lecturer in Engineering & 8 (as teacher), 31 (as an \\
architect) & University \\
\hline
\end{tabular}

Table. 1 Interview partners

Both the first engineer (Eng01) and the teacher in engineering (TeachEng) are the heads of a private architectural company. As they had already been in business prior to the emergence of internet communication, they have experience with a great variety of text forms. The other teacher (TeachHealth) had also been working as a physiotherapist at the university hospital before she became a teacher at the same hospital three years ago. All of the other engineers are employed in larger companies (between 50 and 300 employees). The physiotherapists either work in private practice or are part of a hospital team.

Since most of the professionals (except Eng02) have been working in their field for a certain period of time, their experience of writing at university is, to a certain degree, out-of-date. However, the interviews with those who are also university teachers showed that, with respect to writing, not much has changed in academia in the recent past. Thus, the professionals' impressions still represent the academic reality.

Being able to study physiotherapy at universities in Germany is a relatively recent phenomenon. Until 2001, physiotherapy was viewed exclusively in a practical, vocational sense. Although subjects such as neurology or orthopaedics have always constituted a crucial part of the curriculum, physiotherapy studies were not offered at university nor at universities of applied science but rather at vocational schools. The possibility to study physiotherapy at university was established in 2001 in order to give physiotherapists more legal rights and greater independence in terms of the analysis and treatment of patients. The old system allowed treatment only according to prescriptions received from general practitioners and/or orthopaedists. The physiotherapists we interviewed had all been educated in the 'pre-university' age of physiotherapy and many practitioners expressed concern as to whether university students would be able to perform as successfully in the professional context, as the amount of support university students receive and their training in the practical field are more limited than for those who train at the vocational schools, especially when the education is not provided in dual form (Health03 and 04).

\subsection{Interviews}

Our interviews focused on eliciting a comparison by the professionals of the writing skills taught at university versus the writing skills necessary for their professional careers. We developed an interview script that integrated those aspects from the questionnaire used in a previous study 
(Breuer et al. 2015), which highlighted the largest differences in evaluations by the respective groups (students, teachers, professionals). These aspects were:

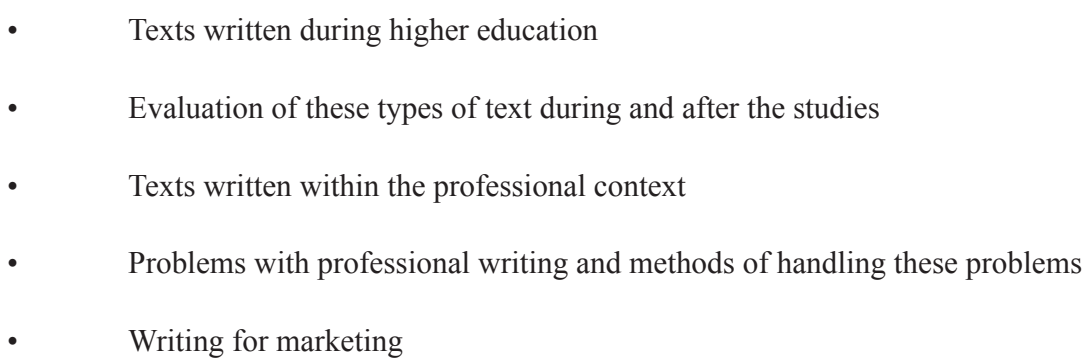

The script provided only an outline for the interviews, which were generally conducted in an informal, conversational manner.

The interviews were conducted in six one-to-one as well as in two dyad settings. The one-toone settings had the practical advantage of being easier to guide and creating less risk of losing focus, but speaking with two professionals at once promised a more 'inspiring' context. The latter setting lost its formal atmosphere while gaining the character of an informal chat. One participant's memories of certain experiences activated memories in the other participant and vice versa, leading on the whole to more elaborate, lively and spontaneous content.

Five interviews took place at the participants' work place in order to make them feel comfortable but also to give them (and the researcher) the opportunity to share professional texts, to take a look not only at the instruments used for writing and creating texts but also at the variety of texts that they receive and work with. The interviews took between 30 minutes and over an hour, depending on the personal involvement in the matter but also - in the case of the physiotherapists - on the free time they had between their sessions with the patients or on the duration of the lunch breaks. Two interviews were conducted online because of the distance between interviewee and interviewer. Here, relevant material was presented via Skype and/or via email exchange. One interview was conducted by telephone because of an unreliable internet connection.

The interviews were audio recorded, and sections of the discussions were then transcribed. For the purposes of this article, we have reduced the material: we have summarised common views, thus constructing logical entities. We have also chosen contradictory views in order to show that professional writing can vary widely depending on the context and on the individual ability and keenness to learn and further develop one's capabilities.

Despite their initial doubt about being able to contribute much to the topic of writing, the interviewees were proactive and their perspectives provided much insight into the different forms of written communication and their impact on the success of these processes.

\section{Results}

The examples are summarised and presented in the categories and sub-categories of "peer-to-peer communication" (professionals interact with other professionals in their field) and "communication with professionals-non-peer audiences" (other professionals and/or (possible) customers). They are then subdivided into the sections of teaching and practising.

\subsection{Outcomes: Peer-to-peer communication}

Teaching of academic writing at university

Neither the health professionals nor the engineers received explicit teaching of written communication. As both TeachHealth and BSc explained, only 16 hours are scheduled for teaching and learning basic academic skills, spread out over the first year. Since so little time is scheduled, teachers need to prioritize. As it is crucial in the professional context to be up-to-date in research and to apply scientific findings, TeachHealth decided to concentrate on teaching students the skills 
required for reading academic texts, as well as interpreting and conducting statistical analyses (a point emphasised also by Health04). The results of the students' work in TeachHealth's class are presented exclusively in oral form. Writing is only used for summarising texts, which students were free to do, either through notes or in the form of longer text. The students receive a huge amount of information but do not have the time to practise the methods and strategies introduced in the class. As this class is taught very early on in the studies, Eng2 complained that he no longer remembered its content at a later stage although this content was necessary to write up his BSc thesis.

Although writing is not taught explicitly in physiotherapy either, writing becomes important in practical classes, as noted by TeachHealth. For example, writing reports is given much attention in classes on the analysis of the incoming patients' physical conditions, as well as on the success of the treatment. Students receive a number of questions that they are to answer and then use to write the final reports. The main aim of the task is to create a text that conveys as much information as possible, in order to provide a complete picture of the patient's condition. According to Health03, neither students nor teachers pay much attention to the logical structure of their texts, as long as the information provided is complete. She stated that the demands of the teachers also differ depending on their own individual style. Although writing reports was done in various medical topics classes, the teachers in these classes worked more or less independently of each other, with the result that no general picture was provided of how to write goal-oriented reports. Interestingly, Health03 evaluated this positively: the lack of structure allows her to adjust her texts to the characteristics of the doctors for whom she nowadays writes, because she does not have a set genre in mind.

This positive viewpoint on the interdiscursive writing performance is by no means shared by everyone. The effect of feedback which relates only to the content of the reports is that the texts become too long, providing unnecessary information:

Everything is noted, from the name of the dog, to which television series the patients watch and so on. Really every detail is written down which might possibly have an impact on the patient's situation. (TeachHealth) ${ }^{1}$

Although these private aspects are vital during treatment (see below Professional-client/patient communication), this information is redundant in the written report, especially if it is written for a doctor who hardly ever reads the reports and rather focuses on the data given to him in the letter (see external professional communication: health professionals-doctors).

\section{Academic peer communication}

None of the participants had written lengthy papers during their formal education. Although 'short' term papers were a requirement for the engineers, their written tasks usually consisted of drawing and calculating. The physiotherapists tended only to write short reports, and most of their exams were multiple-choice tests. None of the interviewees regretted this when they were students, saying that they were "no great writers" (Eng01) or that they lacked the time. Since calculations, drawings and reports were said to be the most relevant written form in their professional lives, the lack of practice in writing different text forms seemed reasonable to them at the time. Now, years later, they do not see any relevant reason to offer more writing practice at university level either, as they still expect their readership to consist exclusively of their peer group. Eng02, for example, complained about the proof-reader of his BSc-paper (who is a graduate of the Arts and Humanities Faculty):

Throughout the paper she wrote in the margins that I should say why I do what I do, and that I have been successful in doing what I wanted to do. But everybody can see that it was successful by just looking at the numbers! (Eng02)

1 For reasons of readability, the quotes are exclusively given in the translated English version. 


\section{Professional-peer communication: engineers}

The engineers stated that they rarely produced any written form of communication with their peers that consists of full sentences. They either call each other, or they send each other technical drawings. They stated that using more words might only create confusion and misunderstandings (Eng02), so it is safer to keep the focus on the "really important" (Eng01) matters.

\section{Professional-peer communication: health professionals}

Health professionals within the hospital context tend to continue writing the elaborate reports practised at university, as they find reports such as these helpful for their own work. It is useful when summarizing what they have done and what worked well, so that they can adjust their treatment to what they learn about the patient in the report. Health04 stated that only detailed reports help him to work effectively when taking over a patient from a colleague. He and his colleagues begin the diagnosis of the patients with a very long and profound interview, which includes biographical data as well as social factors. Since these factors can be relevant for physical problems, having the information helps him to generate an effective treatment plan. It also has an impact on how treatment is seen by the patients and thus its potential success:

There is a reason for the saying that a louse has run over someone's liver [German proverb for somebody who is in a bad mood because of something undefined that has happened to them]. Patients with liver problems are often without drive, and we should keep this in mind.(Health04)

Health04 and his colleagues discuss the individual patients, the various treatments and possible treatment modifications with the doctors. As medical institutions and departments define academic terms differently, they have developed a 'common language' to facilitate understanding. When the physiotherapists and doctors at Health04's hospital receive diagnostic reports from other institutes, they 'translate' these reports in their hospital's internal language, making "grey linguistic areas either black or white" (Health04). They need interdiscursive practice in the professionalprofessional communication within their own community.

However, in larger, privately-led practices, the picture is very different. As described by Health02, a patient is often treated by different physiotherapists, and these do not have the time to take notes after sessions (nor are they paid for doing so), or have the necessary knowledge about the patient to give very detailed descriptions. In managing this challenge, the heads of the two practices in this study have adapted the reports by leaving only very restricted space to answer set questions related to the anamnesis of former illnesses, of applied methods, and of the effects of the method. Filling in these restricted spaces does not require much thought, and is meant to take no more than five minutes.

\subsection{Outcomes: Communication with professional-non-peer audiences}

Writing texts that is read by (future) customers and/ or by patients can become an important aspect in professional lives. The experiences that our participants had in this respect at university and in their professional lives will be outlined below.

\section{Teaching external written communication at university and in the professional context}

As described above, the analysis of the target group, as well as interdiscursive and interdisciplinary 'diplomacy' are highly relevant for the writing process, especially for 'external', that is, non-peer audiences. Yet, these competencies remain neglected. Eng01 and TeachEng, for example, need to write proposals responding to calls for building public buildings (e.g. schools), which are read by members of different fields within the construction business but also by teachers who will work in the buildings and whose interest in structural calculations is only marginal. However, students were not taught to create texts for the real world, in which efficiency or low prices become one's goals (TeachEng). Engineers are thus often confronted with the challenge of having to sell a 
solution with a higher price to a customer if they think that the low-cost variant will not match the expectations of the customer with respect to the product's quality. TeachEng explains that in these cases writing should be more poetic ("lyrischer") so as to convince the customer to use the engineer's choice of materials rather than that which the customer has proposed; in other words, favouring the engineer's ideas.

None of the employed engineers or physiotherapists wrote emails or letters to customers while at university, nor did they do so often in their professional lives. According to TeachHealth, there is a profound lack of communication competency in official written exchange:

I get emails from students which are completely unacceptable. Basic things like greeting or addressing
the other are not applied. Forms of politeness, which are simply part of this kind of conversation, are
usually not mastered by them. I have decided to teach this to them by responding extra correctly. They
eventually get the message after the third email. (TeachHealth).

She helps students by making them write a practice term paper and giving them thorough feedback first, before they have to hand in their final term papers, which are then graded. As mentioned by the engineers and the physiotherapists, this is not common practice and that in their experience, lecturers prefer to complain about the students' writing competencies rather than to offer guidance. Eng03 and Eng04 did not even expect teachers to offer any guidance at all.

When they [the students] come to the university, they should be able to do these things. They should have learned them at school. If they have not learned it there, then the university is not the place to be.(Eng03)

The experienced professionals as well as the pedagogues were aware of the fact that the literacy competencies required for successful professional communication are something many graduates lack (including orthography and punctuation; see also Berninger et al. 2008; Sterling et al. 1998). However, none of the practitioners in this study saw this as a lack within university education, nor did they consider explicit teaching and practice within the professional setting a sensible measure in dealing with the problem.

The teachers were more open to including writing practice into classes. TeachEng, for example, recommended emphasizing the importance of following a certain structure when communicating with customers, e.g. by creating a text with an introduction in which one outlines the suggested change, a main part in which the advantages as well as the disadvantages (for example higher prices) are outlined, and a conclusion in which these are synthesized, leading the customer to agree with the engineer. TeachEng suggested having a class on these kinds of texts, maybe also including standards for writing applications. The engineers are in agreement that there is a lack of competence in the latter aspect, with Eng01 noting succinctly:

The 'best'letters of application are those that are still saved in Word and in which you may read Dad's comments regarding what the kid should enhance in order to make the application a success.(Eng01).

She does not even look at the CVs of these writers, whereas in the companies of the other engineers, these job applicants are still invited to interviews. Still, the engineers explicitly complained about a lack of competency and yet did not see a call for teaching (cf. Neumann 2015).

Aware of these weaknesses, TeachEng and Eng01 use mimesis in coaching their employees. Eng01 stated that she herself learned how to write letters to her clients as well as to write "building diaries" at her first employment in a small architectural office. She was asked to take a look at good examples of such texts, as well as to hand in her own versions before sending them out to craftspersons or to customers.

They did read those kinds of texts. According to the craftspersons, their main motivation was that it could be noted that they had no work, and that they would be fined if they did not work accordingly. But they only read across the text. Style, spelling or punctuation is of no interest to anyone. (Eng01) 
Because she knows how important meeting the readers' demands is, she and TeachEng have adopted the method of teaching their employees to write in an appropriate manner, by giving them not only feedback but also prototype texts. The method of selecting their employees by including an evaluation of their competency in writing an application letter has been quite successful. The engineers do, however, remark that the time the engineer needs to acquire the necessary skills depends on the individual person, with some needing feedback only once, and others taking up to ten times.

\section{External professional communication: health professionals-doctors}

In Germany, doctors tend not to request reports from the private physiotherapy practices. If they do require information on previous treatment, this report will be sent to them. However, Health01 and Health02 presume that many doctors do not actually read these concise reports:

Of course, I hope that some of them read the report. But I believe that most of them ask for the reports in case the health insurance companies make enquiries as to whether the referral had any positive effect. They then can get the report and send it to the health insurance.(Health02)

Knowing that their reports will probably not be read has a negative effect on their motivation to write, and so does the health insurance companies' habit of not paying for the paper work conducted by the physiotherapists either between sessions or during breaks.

Another important factor in external communication is the therapists' insight into their patients' thoughts and feelings. As described by Health02, physiotherapists often find themselves in the challenging situation of having their patients confide that they do not really want their therapy to be successful. Instead, they would prefer to be diagnosed as incurable, thereby allowing them to resign from their jobs and begin early retirement. The physiotherapists are then in the delicate position of having to write reports in which they need to describe their success (otherwise the doctors would not recommend patients to go to this practice), while on the other hand, they need to express their concern about sending the patient back to their everyday job.

It's like dancing on eggs. I cannot claim that I have done my work improperly. At the same time, I can't

abuse my patient's confidence by giving him a whipping.(Health02)

Only Health03, who works in a private institution, has had positive experiences with physicians. She works in a field that has only recently been acknowledged for shoulder/back problems, for headaches and migraines - namely, a medical field related to the phenomenon of grinding teeth at night, which, in turn, has a negative effect on the spine and the nerves connecting the spine and other parts of the body. She states that doctors come to her practice wanting to learn more about how she treats these patients. For Health03, it makes sense to put more effort into the reports for the(se) doctors, to suggest treatment procedures, and to state how to adapt the treatment. However, these positive cases are few and far between. Still, they can be very motivating, and Health03 notices a tendency in younger medical professionals to be open to learning from other fields (which shows that there is also a need for working interdiscursively on their side). However, she would not recommend simply stating that a change of treatment is necessary (which would imply that the steps taken so far have not been efficient), so avoiding that the doctors feel ordered about by someone from a professionally 'lower' rank. Physiotherapists should rather 'propose' that the alternative might also be an option.

Not only in situations like these are diplomatic strategies a useful skill. According to TeachHealth, it is generally important to make a thorough target group analysis of the doctors who receive the recommendations given in the reports. When a specific form of further treatment seems helpful for the patient's development, one needs to know whether the doctors or the institutions who sent the patient appreciate the proposed method, or whether they prefer different methods. In the former case, writing the report is simple, while in the latter case, tact and hedging are necessary. One should first mention the doctors' preferred method as appropriate but then needs to convincingly formulate that in this special case an alternative method would be better. 


\section{Professional-client communication}

Since professionals and clients often do not share the same linguistic repertoire, the demands on professionals' writing skills are high, since they must become proficient in a variety of genres and to address different target groups cost-efficiently. One useful method is integrating images. Eng02 makes elaborate use of them when he gives training courses to his customers, who are technicians but come from different professional backgrounds. He claims that the use of more text leads to unclarity and to an increase in questions from the participants. Since the customers are usually more interested in how to use the product and not in how the product actually works, the success of a product depends in his view on the (operation) instructions and the technical documentation. He evaluates this as one of the main differences between academic communication and professional communication.

Elaborate use of language does not help the patients to understand exercise instructions either. Health 04 therefore makes use of film, allowing the patients to film him while he is performing the exercise, so that they have a model to work with. Trying to do this with words alone is not very useful, as language can be interpreted individually, which is less so the case for films and pictograms.

You stick this on your refrigerator at home and know what you have to do at a glance. (Health04).

Use of images in texts is also useful in the marketing of one's services to a large variety of target groups. Eng01 and TeachEng, for example, create texts for their websites, texts for proposals, and so on. They have solved this problem by reducing the linguistic content as much as possible and by conveying the message multi-modally. This enables them to address both a professional audience and a client audience. Pictures of outstanding elements as well as technical drawings of the buildings give different impressions which meet the different demands. The (linguistic) written information is reduced to a minimum. Here, no professional architectural language is used but rather that of the "well-educated, politically correct reader" (Eng01) - the target group of their clients.

The challenge for physiotherapeutic practices, however, is that they are not able to use pictures in such an elaborate way for marketing purposes. Clients are not willing to be photographed, the physical problems are often invisible, and so is the positive result of the treatment. The differences between the physical treatments are also often visually so subtle that differences between 'manual treatment' and 'massage' cannot be visualised.

There are additionally some legal aspects to keep in mind, as described by Health01. Nowadays, physiotherapists are not legally authorised to do a medical examination or curative treatment without a prescription from a medical practitioner, although they would technically be able to do so. Doctors are sometimes reluctant to refer patients for physiotherapy because of budgetary constraints. Patients often need to wait for appointments with orthopaedists for more than two months. As a result, they often try to access treatment from a physiotherapist without a prescription. However, there are no free curative offers available, which is senseless to patients in pain and who are already past the preventive condition.

\footnotetext{
It's crazy - of course we are able to do analyses. We speak with the people, we examine them. We often do this more elaborately than the doctors. Still, we are not allowed to tell this publicly. Private customers are, however, very important for us because the public health insurance companies pay so little. And of course, people would need it. To couch this diplomatically - this is art! We have paid an agency to do this. But they did not have any idea about the subject.(Health01).
}

This example demonstrates the difficult situation professional writing can impose on writers. On the one hand, health professionals need to promote themselves, while on the other hand legal demands need to be met. The website mirrors this dilemma: the texts are very long, rather academic and unnecessarily elaborate.

In larger companies, managers seem to be more aware of their employees' lacking awareness of interdiscursive writing skills; the result of which is that the engineers often are not the ones 
to communicate with their clients directly but rather the heads of the department, or colleagues from the sales department who exchange emails and the like with the customers. Still, another text form is crucial for the engineer-customer communication, namely the technical specification sheet and the product requirements document. These documents are important, since they form a kind of sub-contract between the customer and the company, which can also be called upon in the case of legal proceedings. Although these various text forms are trained in class, they are not taught in the 'customer-centred' way. As stated above, students need to focus on aspects like the 'ideal' solution for a project, whereas in 'real life' factors like costs and personal preferences might be key factors. Professional engineers can often already estimate whether a job will be done successfully in these conditions. Therefore, they will be extra careful with product requirement documents because if they do not make it clear in the document what can be achieved for the fixed price, they can be asked to do corrections later on. This may create costs that will not be paid by the customers if the document guaranteed a 'perfect' product at the fixed price in the conditions proposed.

If this is not done correctly, the document might lead to another challenging text form for the engineers: the expert's reports. While Eng03 received an extra half-year training for working as a provider of expert evidence, Eng04 did not. He had to learn to write these reports by trial and error:

\begin{abstract}
I wrote the first reports as I thought that it fitted best. It was the answer to a report written by the opposing side which stated that we had committed an error in programming. I simply copied the modality, the language. Then I gave them to our legal department. And they said: we do not understand a word but the language sounds legal enough.(Eng04).
\end{abstract}

Although the legal officers did not understand any of the technical (and very critical) information, the use of language in the legal text is in fact essential in the experts' war ("Gutachterkrieg", Eng04), which is conducted in the form of writing reports, receiving contra reports, writing another contra report, and so on. Although judges are usually trained in the technical aspects if they work in the field, they have more expertise in legal affairs. Choosing the correct words, the fitting structure and so on, can therefore be crucial for the success of a party in legal proceedings.

While writing these texts is in itself time-consuming, this time is often not taken into account by the heads of the department or by the company's management. Eng03 stated that he is in a good position to decline other tasks when he is asked to write reports, since this is a specifically stated, necessary part of his job. Eng04, on the other hand, claimed that the reports are often seen as the consequence of the engineer's improper work (If I had done the job properly, we would not have any complaints, say the ones on top!). In other words, he considers having to write responses to reports an unnecessary burden on his workload.

\title{
5. Discussion
}

The aim of the interviews was two-fold: (1) to take a look at professionals' education in writing, as well as their attitude and approach to writing; (2) to draw conclusions on this information for the teaching and practice of writing competency. The interviews showed that the participants' perception of writing was rather bleak: writing plays a central role in their professional lives, but they do not see much sense in the process, nor did or do they receive sufficient support and appreciation for their written work at university or within the professional context.

Although written exams are crucial for one's educational success, writing is not or only marginally taught at university. It seems that it is still widely seen as 'unteachable' (apart from orthography and punctuation), as described in section 2 (cf. Arrington 1986; Schriver 1997), or as a skill to be learned independently from the course curriculum. As TeachHealth, and Eng02 describe, teaching writing skills, if done at all, does not explicitly stress the importance of the competency within one's professional career. Thus, the students often cannot grasp the fact that different genres are not a corset set by their teachers (Bakhtin 1986) but rather a means to 
communicate more effectively within a group (Swales 2004, see above). As outlined by Health03, feedback is not even given in this respect, although it would help future professionals to adapt their academic genre competencies to other professional contexts and consequently to enhance the communication processes within and across professional groups.

On the contrary, professionals perceive academic writing as not applicable in real life (cf. Breuer et al. 2015). Academic writing is rarely evaluated as an effective instrument to understand future professional processes (Kurunsaari et al. 2015); writing at university is exclusively seen as a time-intensive 'crusade' necessary only for acquiring one's degree.

When students then enter the professional context, writing other types of texts becomes central. Texts different from those written at university need to be produced for an audience that is usually not a peer group (e.g. emails to customers, letters to doctors). According to Health 4, texts also need to be completely re-written sometimes even inside the peer-group, as the status quo in the universities' and institutions' writing presents a rather disturbing depiction (Mead 1998; Redish 1995). If communication within the peer group is already problematic due to an indistinctly performed common genre, this problem is intensified when it comes to writing for other groups. Here, interdiscursive competencies are even more vital (Willerton 2015).

The only way the participants in our study have learned to write within these settings is by using the method of mimesis, that is, by "observation, imitation and rehearsal" (Billet 2015: 28). However, learning through mimetic processes requires an awareness of why things are done the way they are done. It requires learning which aspects form part of one's specific professional genre, and which are only viable for the specialised audience, therefore needing to be interdiscursively adjusted to the readers' professional practice (Bhatia 2010). These issues are not discussed at university nor explicitly supported by managers. This leads to scenarios like that of Eng02, who still does not understand the lecturer's request to add information about the statistical analysis into his text. To him, the statistics suffice, and so they should for his audience. He upholds this viewpoint, even though he has experienced problematic misunderstandings both with his lecturer and in his training classes with customers who will work with his product in the future. One can therefore conclude that by not communicating this mismatch between the information given and the information needed, universities are missing their chance and their duty to support their students' steps into the professional world.

This situation is, however, not criticized by the participants, although they struggle during the text production process. This lack of criticism is possibly the result of the fact that the texts that are produced by professionals are often not perceived as 'real' texts. Here we are confronted with the age-old understanding of written texts as consisting exclusively of sentences. Multimodal texts such as technical drawings or notes (Archer/Breuer, 2015; McMurtrie 2015) are not evaluated as 'real' writing. 'Serious' writing is perceived as something which TeachEng would have called 'poetic': expressing one's thoughts rather eloquently and elaborately, while short, concise and goal-oriented formulation is not highly evaluated, although this is often more demanding than writing word after word without structure and goal (Clyne 1987; Breuer 2013, 2016). Here, one can see the influence of the (old-fashioned) Teutonic way of academic writing that has been practised in Germany (Galtung 1981). Teutonic writing calls for the author to express all of their ideas (however slightly) related to the topic in order to present a broad picture of the topic discussed which stems from the romantic tradition of writing (Schriver 1997). A lack of writing competency, according to this view, mirrors a lack of thinking competency on the side of the writer (Arrington 1986), or (even more so) on the side of the reader who is unable to understand the content (Swales/Feak 1994). This attitude persists, although professional reports have adopted the Saxonic academic genre, which prefers 'selling' academic findings and the conclusions that one has drawn to 'telling' these findings and conclusions (Swales/Feak 1994).

Although managers perceive the lacking ability of their employees to write interdiscursively, they tend not to offer the participants training practice. They rather exclude them from external communication or introduce intermediate communicators with no knowledge about the content. 
As noted by Eng04, the intermediate communicators are employed to evaluate and circulate the texts that he has written, and everyone knows that they do not understand the content and only evaluate whether the formalities of the genre conventions of the target text are met. In other words, whether or not the content is understood is not valued as an essential part of the writing process and the genre conventions by either group. We find ourselves in the absurd situation that interdiscursivity is required but that the crucial reasons for interdiscursivity are lost along the way, namely the combination of "lexico-grammatical, rhetorical and organization" of the text, "the [sensible] conventions of the genre in question", "the professional practice" (Bhatia 2017: 34 ) and the "culture of the profession, discipline, or institution that constrains the use of textual resources for a particular discursive practice" (35) for successful communication. Interdiscursivity is reduced to the application of the conventions of the new genre in the texts; the professional text genre then becomes the same formal corset as the academic genre was before.

The knowledge that being valued as a communicative (writing) partner is conducive to the writing process (Roberts/Cimasko, 2008) seems to be missing among the majority of our participants. Consequently, little motivation could be observed to reflect on or to enhance their writing skills. This lack of motivation results in a vicious circle: the quality of text production does not improve, and the professionals are unwilling to analyse the target group, as they do not see the necessity of revising their texts appropriately (Breuer 2015; Hayes 2012). This further results in miscommunication, negative feedback toward the managers/directors of the institution, and the self-fulfilling prophecy of all participants that bad writers are bad thinkers and that one cannot learn to write (Arrington 1986; Schriver 1997).

Neglecting the importance of proficiency in writing has, however, a negative effect on the workflow in general (Ramey 1995), since the written texts indeed have an impact on the respective company's financial success (Mead 1998) as well as on correspondence in the professional culture (Bhatia 2010). It would, therefore, be sensible to offer classes on professional writing in different contexts already at university - at a later stage in the curriculum. In these classes, the value of the academic texts themselves and the applicability of writing skills in one's professional life can be discussed, and feedback can be given on texts, while making it clear how different target groups might grasp (or not grasp) the texts. Some professionals may learn how to write through practice alone (Eng01; TeachEng), while others are expected to use forms that they need to fill in themselves without any guidelines (Health01 and 02), or they spend time and paper on a text that might not even be read by the target group (Health01 and 02; TeachHealth): it is exactly these areas that would save money if taught and executed successfully (Kimble 1995).

A first step might already consist in stressing in education this relationship between economic success and writing. This can have a very motivating effect, as has become visible in the attitudes of Health03, Eng01 and TeachHealth, who are responsible for making and keeping their organization profitable, and who were subsequently motivated to write in a target-group appropriate way. The architects found ways of showcasing their professional qualities by using interdiscursive methods of diplomacy. They not only use wording and focus of content in their texts that is appreciated by their target group 'teachers' (Sanders/Albers, 2010) but also emphasize their competency by presenting technical but also 'average-reader' appropriate graphs on their website, visually translating architectural drafts into the finished product. It is interesting how their website shows preference of interdiscursive graphs designated to different target groups rather than interdiscursive textual genres. This seems to reflect the most important form of written communication in the architectural field to make expertise visible (Simpson 2016).

Health03 could not resort to images for her website. She needed to formulate her texts in such a way that did not overly stress her expertise but still made clear that she knew what was best - this was necessary because of the German laws that physiotherapists are not yet allowed to offer medical treatment on their homepage (Freisleben-Teutscher 1996). The amount of time she needed to find suitable formulations for her website emphasises again the importance of 
practising interdiscursivity and target group appropriate writing at university and during one's professional life (Redish 1995).

\section{Conclusion and outlook}

The qualitative study presented here aimed to shed light on how engineers and health professionals perceive and process writing in their educational and professional contexts. The focus was on the importance and usefulness they attributed to writing, and whether they had a positive attitude towards writing. Since writing is a central factor for educational as well as professional success, these factors are not only important for the personal well-being of the professionals but also for the economic success of the companies they work for.

The interviews showed that engineers and health professionals spend a large amount of their working time writing, despite a lack of motivation to do so. They do not seem to be provided with the skills and tools to adjust the genre they learned at university to the professional genre(s) that are needed in meeting the target audience. Interdiscursivity skills are nonetheless crucial for successful professional communication in and between professional groups. However, these skills do not seem to be of much relevance in the curriculum, neither are they prominently discussed and fostered within the professional context. The necessity of these skills, and training thereof, do not even appear to be consciously registered by the persons involved. Only those engineers and health professionals who use their written communication not only to attract customers but also to establish the client-base seem to have understood how crucial it is to learn how to write interdiscursively.

In the interests of fostering exchange between different professional groups (and also between members of the respective professions), we would like to make a plea for changing the educational setting and providing the students with more input, by adapting a variety of concepts that have been successfully applied in other countries (e.g. Kurunsaari/Tynjälä/Pürainen 2015; RamírezEcheverry/Dussán/García-Carillo, 2016). This would open doors for the engineers and health professionals to work more closely with colleagues and clients of other business fields.

\section{References}

Archer, Arlene/Breuer, Esther Odilia 2015: Methodological and Pedagogical Approaches to Multimodality in Writing. In Rijlaarsdam, Gert/Olive, Thierry (series eds.), Archer, Arlene/ Breuer, Esther Odilia (eds.), Multimodality in Writing. The State of the Art in Theory, Methodology and Pedagogy. Leiden: Brill, 1-16.

Arrington, Philip 1986: The Traditions of the Writing Process. In Composition Studies 14 (3), 2-10.

Bakhtin, Mikhail 1986 [1979]: The Problem of Speech Genres. In Emerson, Caryl/ Holquist, Michael (eds.), Speech Genres and Other Late Essays. Austin: University of Texas Press, 60-102.

Bennett, Steve 2010: Introducing Cooking for Engineers [online]. https://stevebennett.me/2010/11/26/introducingcooking-for-engineers/. (Accessed 15 May 2018).

Berkenkotter, Carol/ Huckin, Thomas N. 1995: Genre Knowledge in Disciplinary Communication: Cognition, Culture, Power. Hillsdale, NJ: Lawrence Erlbaum.

Berninger, Virginia/ Nielsen, Kathleen/ Abbott, Robert/ Wijsman, Ellen/ Raskind, Wendy 2008: Writing Problems in Developmental Dyslexia: Under-Recognized and Under-Treated. In Journal of School Psychology 46, 1-21.

Bétrancourt, Mireille/ Ortoleva, Giulia/ Billet, Stephen 2015: Writing for Professional Development: An Introduction. In Rijlaarsdam, Gert/Olive, Thierry (series eds.), Ortoleva, Giulia/Bétrancourt, Mireille/Billett, Stephen (eds.), Studies in Writing: Writing for Professional Development. Leiden: Brill, 1-11.

Bhatia, Vijay Kumar 2002: A Generic View of Academic Discourse. In Flowerdew, John (ed.), Academic Discourse. Harlow: Pearson Education, 21-39.

Bhatia, Vijay Kumar 2004: Worlds of Written Discourse: A Genre-Based View. London: Continuum International.

Bhatia, Vijay Kumar 2010: Interdiscursivity in professional communication. In Discourse and Communication 21(1), $32-50$.

Bhatia, Vijay Kumar 2017: Critical Genre Analysis: Investigating interdiscursive performance in professional practice. Oxford: Routledge. 
Billet, Stephen 2015: Learning through Writing: Mimetic Processes in Action. In Rijlaarsdam, Gert/ Olive, Thierry (series eds.), Ortoleva, Giulia/ Bétrancourt, Mireille/ Billett, Stephen (eds.), Studies in Writing: Writing for Professional Development. Leiden: Brill, 12-31.

Boehm, Diane Christian 1993: Mozartians, Beethovians, and the Teaching of Writing. In The Quarterly 15(2), 15-18.

Breuer, Esther Odilia 2013: Idea Generation in L1 and FL Writing. In Archibald, Alasdair (ed.), Multilingual Theory and Practice in Applied Linguistics: Proceedings of the 45th Annual Meeting of the British Association of Applied Linguistics. London: Scitsiugnil Press, 31-34.

Breuer, Esther Odilia 2016: Effects of Planning and Language on the Construction of Meaning. In Double Helix 4, 1-19 [online].

http://qudoublehelixjournal.org/index.php/dh/article/view/91/291. (Accessed 15 May 2018).

Breuer, Esther Odilia/ Newman, Siegried/ Newman, Julian 2015: Learning to Write as a Professional: Engineers and Physiotherapists in Britain and Germany. In Rijlaarsdam, Gert/ Olive, Thierry (series eds.), Ortoleva, Giulia/ Bétrancourt, Mireille/ Billett, Stephen (eds.), Studies in Writing: Writing for Professional Development. Leiden: Brill: 253-275.

Clyne, Michael 1987: Cultural Differences in the Organization of Academic Texts. In Journal of Pragmatics 11, 211247.

Curry, Mary Jane/ Lillis, Theresa 2004: Multilingual Scholars and the Imperative to Publish in English: Negotiating Interests, Demands, and Rewards. In TESOL Quarterly 38(4), 663-688.

Fondiller, Shirley H./ Nerone, Barbara J. 2007: Health Professionals Style Manual. New York: Springer.

Freisleben-Teutscher, Christian F. 1996: Ärztebilder in den Medien. In Multimedia, 25-26.

Funk, Sandra G./ Tornquist, Elizabeth M. 2015: Writing Winning Proposals: For Nurses and Health Care Professionals. New York: Springer.

Galtung, Johan 1981: Structure, culture, and intellectual style: An essay comparing Saxonic, Teutonic, Gallic and Nipponic approaches. In Social Science Information 20(6), 817-856.

Hayes, John R. 1989: Writing Research: The Analysis of a Very Complex Task. In Klahr, David/ Kotovsky, Kevin (eds.), Complex Information Processing. The Impact of Herbert A. Simon. Hillsdale: Lawrence Earlbaum Associates, 209234.

Hayes, John R. 2012: Modelling and Remodelling Writing. In Written Communication 29(3), 369-388.

Henry, Jim 1998: Documenting Contributory Expertise: The Value Added by Technical Communicators in Collaborative Writing Situations. In Technical Communication 45(2), 207-220.

Hering, Heike 2015: Technische Berichte: Verständlich gliedern, gut gestalten, überzeugend vortragen. Wiesbaden: Springer Fachmedien.

Hill, Sandra/ Griswold, Paula 2013: Potential for Collaborative Writing in Professional Communication and Health Studies through Service-Learning. In Business Communication Quarterly 76(1), 54-71.

Holden, Alexander C.L. 2017: Social media and professionalism: does the profession need to re-think the parameters of professionalism within social media. In Australian Dental Journal 62(1), 23-29.

Hyland, Ken 2004: Genre and Second Language Writing. Ann Arbor: The University of Michigan Press.

Juhl, Dietrich 2015: Technische Dokumentation: Praktische Anleitung und Beispiele. Berlin, Heidelberg: Springer.

Kennedy, Mary Lynch/ Smith, Hadley M. 2010: Reading and Writing in the Academic Community. Upper Saddle River: Prentice Hall.

Kimble, Joseph 1997: Writing for Dollars, Writing to Please: The Case of Plain Language in Business, Government and Law. In The Scribes Journal of Legal Language 6, 1-38.

Kurunsaari, Merja/ Tynjälä, Päivi/ Pürainen, Arja 2015: Students' Experiences of Reflective Writing as a Tool for Learning in Physiotherapy Education. In Rijlaarsdam, Gert/ Olive, Thierry (series eds.), Ortoleva, Giulia/ Bétrancourt, Mireille/ Billett, Stephen (eds.), Studies in Writing: Writing for Professional Development. Leiden: Brill, 129-151.

Larson, Magali S. 1977: The Rise of Professionalism: A Sociological Analysis. Berkeley: University of California Press.

Leitjen, Mariëlle/ Van Waes, Luuk/ Schriver, Karen/ Hayes, John R. 2014: Writing in the workplace: Constructing documents using multiple digital sources. In Journal of Writing Research 5(3), 285-337.

Lim, Jae Young 2009: The Effect of Communication between Doctor and Patient on Patient's Medical Care Use. In Applied Economics Letters 16(13-15), 1369-1374.

McMurtrie, Robert J. 2015: Towards a Grammar of System Networks. In Rijlaarsdam, Gert/ Olive, Thierry (series eds.), Archer, Arlene/ Breuer, Esther Odilia (eds.), Multimodality in Writing. The State of the Art in Theory, Methodology and Pedagogy. Leiden: Brill, 86-116. 
Mead, Jay 1998: Measuring the Value Added by Technical Documentation: A Review of Research and Practice. In Technical Communication 45(3), 353-379.

Miller, Carolyn R. 1994: The cultural basis of genre. In Freedman, Aviva/ Medway, Peter (eds.), Genre and the New Rhetoric. London: Taylor and Francis, 67-78.

Morris, M.D. 2009: Professional Expression: To Organize, Write and Manage for Technical communication. New York: Momentum Press.

Mort, Pamela/ Drury, Helen/ Calvo, Rafael A./ Skinner, Ilain/ McEwan, Alistair/ Levy, David/ Molina, Marco Garcia/ Mitrajit, Rudra 2012: An Online Writing Centre for Engineering Students. Proceedings of the Eighth CDIO Conference. Brisbane: Queensland University [online].

http://sydney.edu.au/engineering/latte/docs/12-CDIO-MortDruryCalvo.pdf (Accessed 11 July 2017).

Murrmann, Julia 2015: The idiolect of fitness professional Ewa Chodowska in the context of communication with a target group within the physical activity marketplace. In Baltic Journal of Health and Physical Activity 7(4), 103116.

Neumann, Astrid 2015: Professional Text Genres: Writing Standards in Vocational Education. Studies in Writing 32, 233-252.

Orlova, Irina/ Zeidmane, Anda 2011: Problems in Professional English Writing Skills Development for Students of Engineering Sciences. Engineering for Rural Development - Proceedings of the $10^{\text {th }}$ International Scientific Conference. Jelgava: Latvian University of Agriculture, 520-523.

Pinker, Steven 2014: The Sense of Style: The Thinking Person's Guide to Writing in the 21 ${ }^{\text {st }}$ Century. New York: Penguin.

Ramey, James 1995: What Technical Communicators Think About Measuring Value Added: Report on a Questionnaire. In Technical Communication 42(1), 40-51.

Redish, Janice 1995: Adding Value as a Professional Communicator. In Technical Communication 42(1), 26-39.

Redish, Janice 2010: Technical Communication and Usability: Intertwined Strands and Mutual Influences. Commentary. In IEEE Transactions on Communication 53(3), 191-201.

Ramírez-Echeverry, John Jairo/ Olarte Dussán, Fredy Andrés/ García-Carillo, Agueda 2016: Effects of an educational intervention on the technical writing competence of engineering students. In Ingeniería e Investigacion 36(3), 3949.

Roberts, Felicia/ Cimasko, Tony 2008: Evaluating ESL: Making sense of university professors' responses to second language writing. In Journal of Second Language Writing 17, 125-143.

Rus, Dana 2015: Developing Technical Writing Skills to Engineering Students. In Procedia Technology 19, 1109-1114.

Sanders, Jennifer/Albers, Peggy 2010: Multimodal Literacies: An Introduction. In Albers, Peggy/ Sanders, Jennifer (eds.), Literacies, the Arts and Multimodality. Illinois: National Council of Teachers of English, 1-25.

Schneider, Klaus P. 2010: Sociopragmatic variation and culture-dependent schemata of linguistic behaviour. LAUD paper A748. Duisburg/Essen: University of Duisburg-Essen.

Schriver, Karen 1997: Dynamics in document design: Creating Texts for Readers. New York: Wiley Computer Publishing.

Schriver, Karen 2012: What we know about expertise in professional communication. In Berninger, Virginia W. (ed.), Past, present, and future contributions of cognitive writing research to cognitive psychology. New York: Psychology Press, 275-312.

Shanley, John Patrick 1986: Moonstruck: Shooting Script. Metro Goldwyn Meyers [online]. http://www.pages.drexel. edu/ ina22/splaylib/Screenplay-Moonstruck.pdf (Accessed 07 July 2017).

Simpson, Zachary 2016: Drawn Writing: The Role of Written Text in Civil Engineering Drawing. In Fidalgo, Ruth/ Olive, Thierry (series eds.), Archer, Arlene/ Breuer, Esther Odilia (eds.), Multimodality in Higher Education. Leiden: Brill, 241-255.

Sterling, Christopher M./ Farmer, Marion/ Riddick, Barbara/Morgan, Steven/ Matthews, Catherine 1997: Adult dyslexic writing. In Dyslexia 4, 1-15.

Swales, John 1990: Genre Analysis - English in Academic Settings. Cambridge: Cambridge Applied Linguistics.

Swales, John 2004: Research Genres: Exploration and Applications. Cambridge: Cambridge University Press.

Swales, John Feak, Christine B. 1994: Academic Writing for Graduate Students: Essential Tasks and Skills: A Course for Nonnative Speakers of English. Ann Arbor: University of Michigan Press.

Thielmann, Winfried 2009: Deutsche und englische Wissenschaftssprache im Vergleich: Hinführen - VerknüpfenBenennen. Heidelberg: Synchronwissenschaftsverlag der Autoren. 
Usher, Kim/ Woods, Cindy/ Casellac, Eva / Glass, Nel/ Wilson, Rhonda/ Mayner, Lidia/ Jackson, Debra/ Brown, Jane/ Duffy, Elaine/ Mather, Carey/ Cummings, Elizabeth/ Irwin, Pauletta 2014: Australian health profession students use of social media. In Collegian 21, 95-101.

Willerton, Russell 2015: Plain Language and Ethical Action. A Dialogic Approach of Technical Content in the 21 $1^{\text {st }}$ Century. New York: Routledge. 